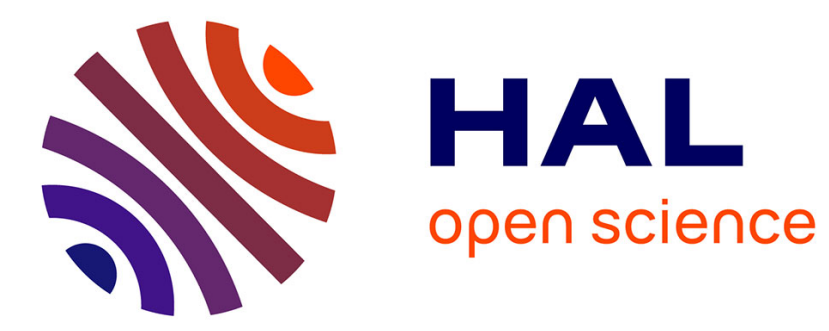

\title{
Numerical results and Biot theory in anisotropic porous/fibrous media
}

Bernard Castagnede, C. Depollier

\section{To cite this version:}

Bernard Castagnede, C. Depollier. Numerical results and Biot theory in anisotropic porous/fibrous media. Journal de Physique IV Proceedings, 1994, 04 (C5), pp.C5-183-C5-186. 10.1051/jp4:1994534 . jpa-00253029

\section{HAL Id: jpa-00253029 https://hal.science/jpa-00253029}

Submitted on 1 Jan 1994

HAL is a multi-disciplinary open access archive for the deposit and dissemination of scientific research documents, whether they are published or not. The documents may come from teaching and research institutions in France or abroad, or from public or private research centers.
L'archive ouverte pluridisciplinaire HAL, est destinée au dépôt et à la diffusion de documents scientifiques de niveau recherche, publiés ou non, émanant des établissements d'enseignement et de recherche français ou étrangers, des laboratoires publics ou privés. 


\title{
Numerical results and Biot theory in anisotropic porous/fibrous media
}

\author{
B. CASTAGNÈDE and C. DEPOLLIER
}

Laboratoire d'Acoustique de l'Université du Maine (LAUM), URA 1101, Avenue Olivier Messiaen, BP. 535, 72017 Le Mans, France

Biot theory [1] is a basic tool when studying the propagation of elastic waves in porous/fibrous solids. Due to the simplicity of the assumptions, isotropic materials are most of ten utilized [2,3]. However, in some cases, anisotropy has to be included in the modelization, e.g. with some fibrous materials. In this work, we have developped routines, based on the standard Biot model, which compute the various characteristic surfaces (slowness, phase and group velocities) [4] in a given plane for anisotropic porous media. By increasing the weight of the coupling constants, one can continuously vary from the limit case of anisotropic solids with no porosity to a number of different porous media. When the coupling terms are not equal to zero, one finds four instead of three propagating modes, the two other eigenvalues being complex, meaning in turns that the two remaining solutions do correspond to some evanescent modes. The slow transverse mode is unchanged. The fourth mode often called the Biot mode [5],. which is very similar to the pseudo-thermal wave $[6,7]$ observed in dynamic thermoelasticity, has always a very small wavespeed and is very highly damped.

\section{BIOT THEORY AND ANISOTROPY}

One starts from the linear elasticity behaviour equation written down in tensorial form:

$$
\left[\begin{array}{c}
\sigma_{i j} \\
\sigma
\end{array}\right]=\left[\begin{array}{cc}
C_{i j k l} & Q_{i j} \delta_{i j} \\
Q_{k l} \delta_{k l} & R
\end{array}\right]\left[\begin{array}{c}
\varepsilon_{k l} \\
\varepsilon
\end{array}\right],
$$

where $\mathrm{i}, \mathrm{j}, \mathrm{k}, \mathrm{I}=1,2,3$, and where $\sigma_{\mathrm{ij}}$ and $\sigma$ represents the stresses in the solid and in the fluid, $\varepsilon_{\mathrm{kl}}$ and $\varepsilon$ being the corresponding strains. The elasticity tensor is denoted by $\mathrm{C}_{\mathrm{ijk}}$, the 
compressibility coefficient of the fluid by $R$, and $Q$ is the diagonal coupling coefficient. Next, the equations of motion respectively of the solid and fluid phases are written as:

$$
\begin{gathered}
\rho_{11} \frac{\partial^{2} u_{i}^{s}}{\partial t^{2}}+\rho_{12} \frac{\partial^{2} u_{i}^{f}}{\partial t^{2}}=C_{i j k 1} \frac{\partial^{2} u_{i}^{s}}{\partial x_{j} \partial x_{k}}+Q_{i i} \frac{\partial^{2} u_{l}^{f}}{\partial x_{i}^{2}} \\
\rho_{12} \frac{\partial^{2} u_{i}^{s}}{\partial t^{2}}+\rho_{22} \frac{\partial^{2} u_{i}^{f}}{\partial t^{2}}=Q_{i i} \frac{\partial^{2} u_{i}^{S}}{\partial x_{j}^{2}}+R \frac{\partial^{2} u_{l}^{f}}{\partial x_{i} \partial x_{l}},
\end{gathered},
$$

where $u$ represent the displacement fields of the solid phase (S) and of the fluid (f), and where $\rho_{11}, \rho_{22}$ et $\rho_{12}$ respectively are the densities of the solid, of the fluid and a coupling term such that $\rho_{11} \rho_{11}-\rho_{12}^{2}>0$. The next step deals with searching solutions in the form of plane waves, i.e. $u_{i}=\exp j(\omega t-k x)$.

Adding dissipative terms to equations (2) results in introducing complex densities (e.g. $\tilde{\rho}_{11 k}=\rho_{11 k}-j\left(b_{k} / \omega\right)$, where $b_{k}$ are the components of the viscosity tensor). In such a case, the wavespeeds are complex and dispersive. We restrict here to the simplier case of real densities, which is however sufficient to describe the main features of related to anisotropy. Writing down the calculations yields the following compatibility equation :

$$
\operatorname{det}=\left|\begin{array}{cccccc}
\Gamma_{11-}-\rho_{11} \mathrm{~V}^{2} & \Gamma_{12} & \Gamma_{13} & \Gamma_{14}-\rho_{12} \mathrm{~V}^{2} & \Gamma_{15} & \Gamma_{16} \\
\Gamma_{12} & \Gamma_{22}-\rho_{11} \mathrm{~V}^{2} & \Gamma_{23} & \Gamma_{24} & \Gamma_{25}-\rho_{12} \mathrm{~V}^{2} & \Gamma_{26} \\
\Gamma_{13} & \Gamma_{23} & \Gamma_{33}-\rho_{11} \mathrm{~V}^{2} & \Gamma_{34} & \Gamma_{35} & \Gamma_{36}-\rho_{12} \mathrm{~V}^{2} \\
\Gamma_{14-}-\rho_{12} \mathrm{~V}^{2} & \Gamma_{24} & \Gamma_{34} & \Gamma_{44}-\rho_{22} \mathrm{~V}^{2} & \Gamma_{45} & \Gamma_{46} \\
\Gamma_{15} & \Gamma_{25}-\rho_{12} \mathrm{~V}^{2} & \Gamma_{35} & \Gamma_{45} & \Gamma_{55}-\rho_{22} \mathrm{~V}^{2} & \Gamma_{56} \\
\Gamma_{16} & \Gamma_{26} & \Gamma_{36}-\rho_{12} \mathrm{~V}^{2} & \Gamma_{46} & \Gamma_{56} & \Gamma_{66}-\rho_{22} \mathrm{~V}^{2}
\end{array}\right|=0 .(3)
$$

In such equation, $V$ represents the phase wavespeed $(V=k / \omega)$, and the terms $\Gamma_{i l}$ are linked to $\mathrm{C}_{\mathrm{ijkl}}, \mathrm{R}$, et $\mathrm{Q}$. For instance, the $\Gamma$ components of the top left $3 \times 3$ subdeterminant is nothing else than the Christoffel tensor, i.e. $\Gamma_{i l}=C_{i j k l} n_{j} n_{k}$, where $i, j, k, 1$ $=1,2,3$, where $\mathbf{n}$ is the wavevector direction. The full determinant has 4 real roots corresponding to propagating modes as well as two additional imaginary roots which do not contribute to the propagation. By supposing the propagation to take place in plane $(1,3)$ of a transverse isotropic solid where $n_{1}=\cos \theta, n_{2}=0$, et $n_{3}=\sin \theta$, then the above determinant has the simplier form :

$$
\operatorname{det}=\mathrm{V}^{2}\left[\left(\rho_{11} \rho_{22}-\rho_{12}^{2}\right) \mathrm{V}^{2}-\rho_{22} \Gamma_{22}\right]\left|\begin{array}{cccc}
\Gamma_{11}-\rho_{11} \mathrm{~V}^{2} & \Gamma_{13} & \Gamma_{14}-\rho_{12} \mathrm{~V}^{2} & \Gamma_{16} \\
\Gamma_{13} & \Gamma_{33}-\rho_{11} \mathrm{~V}^{2} & \Gamma_{34} & \Gamma_{36}-\rho_{12} \mathrm{~V}^{2} \\
\Gamma_{14-}-\rho_{12} \mathrm{~V}^{2} & \Gamma_{34} & \Gamma_{44}-\rho_{22} \mathrm{~V}^{2} & \Gamma_{46} \\
\Gamma_{16} & \Gamma_{36}-\rho_{12} \mathrm{~V}^{2} & \Gamma_{46} & \Gamma_{66}-\rho_{22} \mathrm{~V}^{2}
\end{array}\right|=0 \text { (4) }
$$


where

$$
\begin{aligned}
\Gamma_{11}= & C_{11} n_{1}^{2}+C_{44} n_{3}^{2} ; \Gamma_{14}=M n_{1}^{2} ; \Gamma_{16}=M_{1} n_{3} \\
\Gamma_{22}= & C_{66} n_{1}^{2}+C_{44} n_{3}^{2} ; \Gamma_{34}=Q_{1} n_{3} ; \Gamma_{36}=Q n_{3}^{2} \\
\Gamma_{33}= & C_{44} n_{1}^{2}+C_{33} n_{3}^{2} ; \Gamma_{44}=R_{1}^{2} ; \Gamma_{46}=R_{1} n_{3}, \\
& \Gamma_{13}=\left(C_{13}+C_{44}\right) n_{1} n_{3} ; \Gamma_{66}=R_{3}^{2}
\end{aligned}
$$

with $M=Q_{11}=Q_{22}$, et $Q=Q_{33}$.

Accordingly, there exists a trivial root, i.e. $V=\left\{\rho_{22} \Gamma_{22} / \rho_{11} \rho_{22}-\rho_{12}^{2}\right\}^{1 / 2}$, which is identical to $(\Gamma 22 / \rho 11)(1 / 2)$ when $\rho 12=0$, which is the wavespeed of the pure transverse mode. Some significant numerical results obtained with the above procedure are plotted on the Figure. Further details are provided in reference [8].

\section{CITED LITERATURE}

[1] M.A. BIOT, Acoustics, elasticity, and thermodynamics of porous media, twenty-one papers by M.A. BIOT, edited by I. TOLSTOY, American Institute of Physics, 1992.

[2] J.F. ALLARD, Propagation of sound in porous media, Elsevier, London, 1993.

[3] C. DEPOLLIER, Théorie de Biot et prédiction des propriétés acoustiques des matériaux poreux. Propagation dans les milieux désordonnés. Doctorat ès Sciences, Université du Maine, 1989.

[4] B.A. AULD, Acoustic fields and waves in solids, Wiley, New York, Vol.1, $2^{\text {nd }}$ edt., 1990, p. 221-236.

[5] T.J. PLONA, Observation of the second bulk compressional wave in a porous medium at ultrasonic frequencies, Appl. Phys. Lett. 36, 1980, p. 259-261.

[6] D.K. BANERJEE et Y.-H. PAO, Thermoelastic waves in anisotropic solids, J. Acous. Soc. Amer. 56, 1974, p. 1444-1454.

[7] W. NOWACKI, Dynamic problems of thermoelasticity, Polish Scientific Publ, Warszawa, 1975.

[8] B. CASTAGNEDE et C. DEPOLLIER, Surfaces caractéristiques pour un matériau poreux anisotrope dans le cadre de la tgéorie de Biot, C. R. Acad. Sci. Paris II 317, 1007-1013 (1993).

\section{CAPTION FOR THE ILUSTRATION}

Figure : Characteristic surfaces (wavespeed curves) in plane $(1,3)$ of a transversely isotropic porous material. The properties of the material are the following:

$C_{11}=26.1 \mathrm{GPa} ; C_{33}=65.5 \mathrm{GPa} ; C_{44}=10.5 \mathrm{GPa} ; C_{66}=8.50 \mathrm{GPa} ; C_{13}=9.58 \mathrm{GPa}$;

$C_{12}=C_{11}-2 C_{66}=9.31 \mathrm{GPa} ; \rho_{11}=2.108 \mathrm{~g} / \mathrm{cm}^{3} ; \rho_{22}=1 \mathrm{~g} / \mathrm{cm}^{3} ; \rho_{12}=0.1 \mathrm{~g} / \mathrm{cm}^{3}$.

a) $M=Q=R=0.5 S I$; b) $M=Q=7.5 S I ; R=5 S I$.

The solid lines represent the group wavespeeds.The dashed lines represent the phase wavespeeds.The slow transverse mode nearly has identical phase and group wavespeeds. 

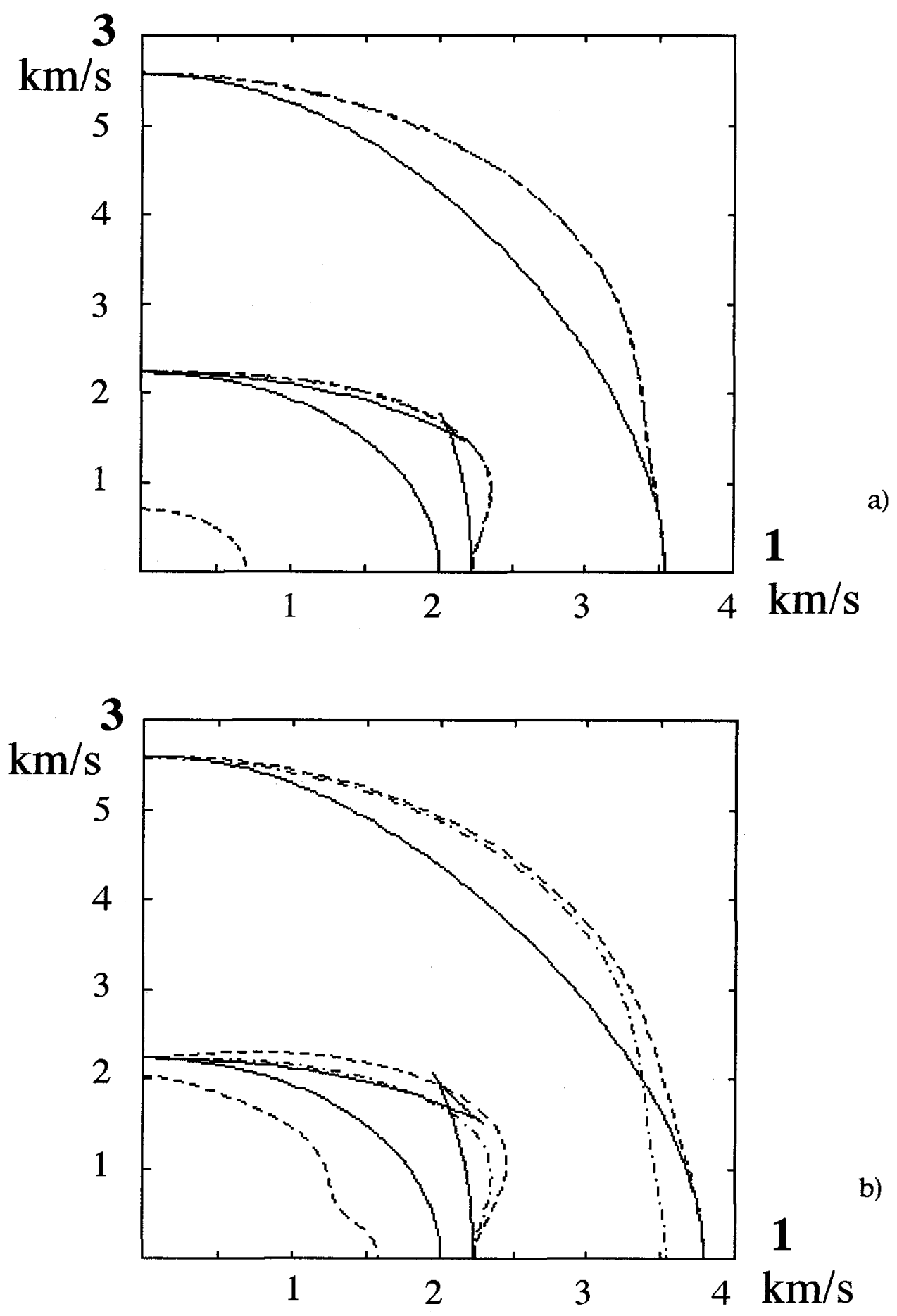